\title{
Comparison of Gram stain and Pap smear procedures in the diagnosis of bacterial vaginosis
}

\author{
Enver Vardar'1, Izzet Maral², Murat Inal², Özgül Özgüder', \\ Funda Tasli ${ }^{1}$ and Hakan Postaci ${ }^{1}$ \\ ${ }^{1}$ Pathology Department, SSK Izmir Training Hospital, \\ ${ }^{2}$ SSK Ege Maternity Hospital, Izmir, Turkey
}

\begin{abstract}
Objective: The purpose of this study was to examine the characteristics of Gram stain versus Pap smear in diagnosis of bacterial vaginosis (BV).

Methods: One-thousand and sixty women were enrolled in this study. All cases with symptoms of BV were determined by Amsel's criteria, which were accepted as the gold standard for diagnosis of BV. Pap smear and Gram stain evaluations were compared according to Amsel's criteria, without viewing the clinical results of the patients. Gram stain and Pap smear results were determined as negative or positive according to Amsel's criteria. Sensitivity, specifity and positive predictive values were calculated.

Results: After accepting the cases that were diagnosed as BV according to Amsel's criteria as reference cases, the sensitivity of the Gram stain method was calculated as $97 \%$ and the sensitivity of the Pap smear method as $93 \%$. Similar specificity rates were obtained with both methods in diagnosis of BV related to the clinical results. There were no statistically significant differences in diagnosis of BV between these two groups.

Conclusion: If Amsel's criteria are accepted as the gold standard for diagnosis of BV, Gram stain and Pap smear methods will give similar results in diagnosis.
\end{abstract}

Key words: Bacterial Vaginosis; Gram Stain; Pap Smear

The most frequently encountered complaint in gynecological out-patient clinics is vaginal discharge. Normal vaginal mucosa does not have any glandular structure. Usually there is a biological balance in the microorganisms living in vaginal mucosa. The most important role in the continuity of this balance - and in preventing the growth of pathogenic microorganisms - is that of Lactobacillus species. Lactobacilli produce an acidic medium in the vagina via hydrogen peroxide $\left(\mathrm{H}_{2} \mathrm{O}_{2}\right)$, which transforms glycogen present in vaginal epithelium to lactic acid ${ }^{1}$. The acidic medium produced by lactobacilli suppresses the growth of other microorganisms. If the balance of vaginal flora is altered against lactobacilli, a clinical picture of itching, pain and vaginal discharge or smell will be observed. In bacterial vaginosis (BV), microorganisms that are short, rod-like and mostly anaerobic, with variable Gram stain properties - such as Gardnerella vaginalis, Bacteriodes, $\beta$-streptococci and the Mobilincus-Falcivibrio group - replace the usual vaginal flora formed by lactobacilli ${ }^{1,2}$.

The aim of the presented study is to compare the efficacy of Gram stain and Pap smear with that of Amsel's criteria in the diagnosis of BV - which is continually gaining importance in relation to morbidity and mortality problems - in cervicovaginal specimens obtained in routine controls. 


\section{MATERIALS AND METHODS}

Routine gynecologic examinations of 1060 patients aged $18-50$ years, who were referred to the SSK Ege Maternity Hospital between July and December 1996 with complaints of bad-smelling vaginal discharge, itching and pain, were performed and histories of the patients were taken. Women using oral contraceptives and vaginal spermicides, those who used antibiotics or vaginal suppositories for any reason and those who performed vaginal lavage after coitus were excluded from the study (172 women).

Vaginal inspections were carried out using a dry, sterile speculum without applying antiseptic cleansing liquids and the characteristics of the vaginal discharge were evaluated. The $\mathrm{pH}$ of the vaginal discharge was evaluated with litmus paper (Merck KGaA Acilit pH, Darmstad, Germany). An amine test was performed to the appropriately taken vaginal discharge sample with $10 \% \mathrm{KOH}$. Samples were taken from the vaginal lateral wall and posterior fornix with brushes, and spread out on three preparations. One of these preparations was examined immediately by light microscope; appropriate fixation, Gram stain and classic Papanicolaou (Pap) stain were applied to the other preparations.

The evaluation of the results obtained from Pap and Gram stains was based on positivity by Amsel's criteria. For a positive diagnosis of $\mathrm{BV}$, the presence of at least three of the following four criteria of Amsel is required: (1) thin, homogeneous gray-white discharge on the vaginal wall, that can be easily sampled; (2) vaginal-discharge $\mathrm{pH}$ above 4.5; (3) observation of 'clue' cells in fresh vaginal smear; and (4) amine smell similar to that of stale fish, obtained by dripping $10 \% \mathrm{KOH}$ on the vaginal discharge ${ }^{2}$.

The aim of the study did not include establishing the prevalence of $\mathrm{BV}$ in the population.

In evaluation of Pap stain under $\times 400$ magnification, according to the method of Davis and colleagues $^{3}$, cases with the presence of microorganisms other than lactobacilli in a thin film form, the presence of clue cells - which are formed by the covering of the cytoplasmic membranes of squamous cells by non-Lactobacillus microorganisms - and a predominance of nonLactobacillus bacteria in most areas, were accepted as
BV-positive cases. Davis and colleagues reported the condition of absence of lactobacilli as a fourth diagnostic criterion, but the absence of lactobacilli is modified as predominance of non-Lactobacillus bacteria over lactobacilli in the present study.

In evaluation of Gram stain under $\times 400$ magnification, according to Thomason and colleagues' 'clue cell' method ${ }^{4}$ cases with the presence of non-Lactobacillus bacteria in most areas and the presence of clue cells in at least two of 20 areas in large magnification, were accepted as positive. Cells having only lactobacilli in their cytoplasm were accepted as negative, whereas the covering of cytoplasmic membranes by non-Lactobacillus bacteria was used to identify clue cells.

Cytologic evaluation related to each case was performed, without any data obtained via Amsel's criteria. Specifity, sensitivity and predictive values of the results obtained from Pap and Gram stains were calculated by using the results obtained according to Amsel's criteria as reference values.

\section{RESULTS}

The mean age of subjects was 31.7 years (range 18-51 years). Approximately forty-seven percent of all cases (416/888) were pregnant at the time of examination. In the pregnant group, the mean pregnancy number of the 416 cases with a determined pregnancy number was 3.4 , and the mean parity of cases with a determined parity was 2.2.

BV was found by Amsel's criteria in 260 (29.3\%) of the 888 cases. In BV-positive cases, the most frequently applied contraception methods of the non-pregnant women were intra-uterine device (IUD) (37\%), coitus interruptus (17\%) and condom (14\%); 19\% were not using any contraception.

All of the women were suffering from vaginal discharge, which was a yellow-gray discharge in $78 \%$ of cases, white in $17 \%$ and yellow-green in $4 \%$. Itching was observed in $88 \%$ and bad smell was observed in $96 \%$. Post-coital odor was observed in $97 \%$.

Two hundred and forty-two cases were determined as BV-positive by Pap smear, compared with $251 \mathrm{BV}$-positive cases determined by Gram stain (Tables 1 and 2). Sensitivity and specifity were 93\% and 94\% respectively with Pap smear and 97\% 
Table I Distribution of positive cases according to diagnosis method

\begin{tabular}{lc}
\hline Diagnosis method & $\begin{array}{c}B V+v e \text { cases } \\
\text { (260 according to Amsel) }\end{array}$ \\
\hline Gram & \\
True $(+)$ cases & 251 \\
False $(-)$ cases & 9 \\
Pap & \\
True $(+)$ cases & 242 \\
False $(-)$ cases & 18 \\
\hline
\end{tabular}

$\mathrm{BV}$, bacterial vaginosis

Table 2 Distribution of negative cases according to diagnosis method

\begin{tabular}{lc}
\hline & $\begin{array}{c}\text { BV -ve cases } \\
\text { Diagnosis method }\end{array}$ \\
\hline Gram & \\
True $(-)$ cases & 593 \\
False $(+)$ cases & 35 \\
Pap & \\
True $(-)$ cases & 588 \\
False $(+)$ cases & 40 \\
\hline
\end{tabular}

$\mathrm{BV}$, bacterial vaginosis

and 94\%, respectively with Gram stain. Positive predictive values were determined as $86 \%$ for the Pap-smear method and 88\% for the Gram stain method. The comparison of results obtained from both groups with Amsel's criteria did not yield any significant difference.

\section{DISCUSSION}

$\mathrm{BV}$ is the most frequent cause of vaginitis, and is characterized by increase in growth of anaerobic and aerobic microorganisms due to an unbalanced eco-system in the vagina ${ }^{2}$. Gardner and Dukes ${ }^{5}$ were the first to report Haemophilus vaginalis as a cause of nonspecific vaginitis in 1955. It is also reported that there are high sensitivity and specifity values of Gram stain in diagnosis of $\mathrm{BV}$, besides Amsel's criteria ${ }^{2,4,6-12}$.

The clinico-pathologic condition characterized by redness in the vaginal wall, bad-odored discharge and the presence of clue cells in cervicovaginal specimens, which results from the transformation of the acidic vaginal $\mathrm{pH}$ to an alkaline $\mathrm{pH}$ via metabolic activity of the aforedefined bacteria is known as $\mathrm{BV}^{6}$.

It is also reported that $\mathrm{BV}$ causes premature rupture of membranes, preterm delivery and endometritis and, according to some authors, BV has possible carcinogenic effects due to abnormal vaginal cytology and mosaic colposcopic pattern in the cervix ${ }^{13-17}$.

Various methods have been recommended for the evaluation of preparations for BV by Gram stain. Spiegel and colleagues ${ }^{18}$ counted a total of 20 areas in $\times 1000$ magnification in which they reported the diagnosis of $\mathrm{BV}$, in correlation with the number of microorganisms present in each large magnification area. Nugent and colleagues ${ }^{19}$ determined a total score over six as BV, by taking Lactobacillus Gardnerella and other microorganisms into account in a total of 20 large magnification areas in $\times 1000$ magnification. In the present study, the clue cell method of Thomason and colleagues ${ }^{4}$ has been used.

Platz-Christensen and colleagues ${ }^{9}$ ascertained the sensitivity of the Pap smear method as $88 \%$, the specifity as $97 \%$ and positive predictive value as 97\%, following a study comparing Pap smear and Gram stain methods in the diagnosis of BV. These rates were $100 \%, 97 \%$, and $94 \%$ respectively for the Gram stain method ${ }^{9}$. In our study, the observed sensitivity and specificity were $93 \%$ and $94 \%$ respectively for Pap smear, and 97\% and 94\% respectively for Gram stain. The positive predictive values were determined as $86 \%$ for Pap smear and $88 \%$ for Gram stain. The aforementioned rates are similar to rates determined by PlatzChristensen and colleagues ${ }^{9}$. But the specificity rate of our study is smaller than the that determined by Platz-Christensen and colleagues. Also, PlatzChristensen and colleagues reported the sensitivity as $90 \%$ and specificity as $97 \%$ after the comparison of Pap smear and clinical criteria, in a similar study performed in $1989^{20}$.

Davis and colleagues ${ }^{3}$ reported the sensitivity and specificity rates of Pap smear as 55 and 98\% respectively, in a study in which the Gram stain results were accepted as the diagnostic standard. They reached their hypothesis because of lower rates of sensitivity. Davis and colleagues claimed 
that the fact that Pap smear screening is a routine procedure and cannot be always evaluated by cytopathologists was the cause of lower rates of sensitivity. But the Pap smear evaluation criteria given to the cytotechnicians, despite a long period of training may explain the different results in Davis and colleagues' study.

Platz-Christensen and colleagues obtained similar results in two studies performed 6 years apart $^{9,20}$. In addition, Prey ${ }^{21}$ reported the necessity of the presence of coccobacilli-type microorganisms for the diagnosis of BV by Pap smear. Bedrossian and colleagues ${ }^{22}$ reported that Pap smear gives results as good as Gram stain in the diagnosis of BV and cervicitis. They also reported that the exclusion of Gram stain from the routine examination method might decrease the economic cost. Lamont and colleagues reported the sensitivity and specificity as 81 and 91\% respectively, in Pap smears evaluated by cytotechnicians, but these rates were 87 and 97\% respectively in Pap smears evaluated by only one cytopathologist ${ }^{8}$.

Long Gram stain evaluation under $\times 1000$ magnification, proposed by Nugent ${ }^{19}$ and Spiege $^{18}$ despite Pap smear evaluation at $\times 400$ magnification, will cause a significant loss of time especially in countries like Turkey, where cytotechnologists are not employed or do not exist. This time-loss will lead to an increase in the cost per preparation, and possibly a decrease in the time that can be used for the determination of malignancies - especially of cervix carcinoma earlier in Pap smear determinations, if the chance of the Pap smear picking up other infection types is also taken into account. The difference between Gram stain and Pap smear methods, especially in specifity in BV diagnosis, can be neglected. If there is a negligible difference between Gram stain and Pap smear methods it is better to use Pap smears in routine gynecologic cytologic examinations.

\section{REFERENCES}

1. Klebanoff SJ, Hillier SL, Eschelbach DA, Waltersdorph AM. Control of the microbial flora of the vagina by $\mathrm{H}_{2} \mathrm{O}_{2}$-generating lactobacilli. J Infect Dis 1991;164:94-100

2. Amsel R, Totten PA, Spiegel CA, et al. Nonspecific vaginitis. Diagnostic criteria and microbial and epidemiologic associations. Am J Med 1983;74: 14-22

3. Davis JD, Connor EE, Clark P, et al. Correlation between cytologic results and Gram stain as diagnostic tests for bacterial vaginosis. Am J Obstet Gynecol 1997;177:532-5

4. Thomason JL, Anderson RJ, Gelbart SM, et al. Simplified Gram stain interpretive method for diagnosis bacterial vaginosis. Am J Obstet Gynecol 1992;167:16-19

5. Gardner H, Dukes CD. Haemophilus vaginalis, a newly defined specific infection previously classified 'nonspecific vaginosis'. Am J Obstet Gynecol 1955;69:962-76

6. Priestley CJ, Kinghorn GR. Bacterial vaginosis. $\mathrm{Br}$ J Clin Pract 1996;50:331-4

7. Thomason JL, Gelbart SM, Anderson RJ, et al. Statistical evaluation of diagnostic criteria for bacterial vaginosis. Am J Obstet Gynecol 1990;162: 155-60
8. Lamont RF, Hudson EA, Hay PE, et al. A comparison of the use of Papanicolaou-stained cervical cytological smears with Gram-stained vaginal smears for the diagnosis of bacterial vaginosis in early pregnancy. Int J STD AIDS 1999;10:93-7

9. Platz-Christensen JJ, Larsson PG, Sundstrom E, Wiqvist N. Detection of bacterial vaginosis in wet mount, Papanicolaou-stained vaginal smears and in Gram-stained smears. Acta Obstet Gynecol Scand 1995;74:67-70

10. Saharan SP, Surve C, Raut V, Bhattacharya M. Diagnosis and prevalence of bacterial vaginosis. J Postgrad Med 1993;39:72-3

11. Eschenbach DA, Hillier S, Critchlow C. Diagnosis and clinical manifestations of bacterial vaginosis. Am J Obstet Gynecol 1988;158:819-28

12. Joesoef MR, Hillier SL, Josodiwondo S, Linnan M. Reproducibility of a scoring system for Gram stain diagnosis of bacterial vaginosis. J Clin Microbiol 1991;29:1266-71

13. Paavonen J, Heinonen PK, Aine R, et al. Prevalence of nonspecific vaginitis and other cervicovaginal infections during the third trimester of pregnancy. Sex Trans Dis 1986;13:5-8

14. Goncales-Falco J, Jurado M, Madambra AM, Oriol A. Gardnerella vaginalis and mosaic colposcopic 
pattern of the cervix: casual or causal association? Gynecol Obstet Invest 1986;121:108-10

15. Pavic N. Is there a local production of nitrosamines by the vaginal microflora in anaerobic vaginosis/ trichomoniasis? Med Hypotheses 1984;15:433-6

16. Hauth JC, Goldenberg RL, Andrews WW, et al. Reduced incidence of preterm delivery with metronidazole and erythromycin in women with bacterial vaginosis. N EnglJ Med 1995;333:1732-6

17. Hillier SL, Nugent RP, Eschenbach DA, et al. Association between bacterial vaginosis and preterm delivery of low-birth-weight infant. N Engl J Med 1995;333:1737-42

18. Spiegel CA, Amsel R, Holmes KK. Diagnosis of bacterial vaginosis by direct Gram stain of vaginal fluid. J Clin Microbiol 1983;18:170-7

RECEIVED 07/06/00; ACCEPTED 04/01/02
19. Nugent RP, Krohn MA, Hillier SL. Reliability of diagnosing bacterial vaginosis is improved by a standardized method of Gram stain interpretation. J Clin Microbiol 1991;29:297-301

20. Platz-Christensen JJ, Larsson PG, Sundstrom E, Bondeson L. Detection of bacterial vaginosis in Papanicolaou smears. Am J Obstet Gynecol 1989; 160:132-3

21. Prey M. Routine Pap smears for the diagnosis of bacterial vaginosis. Diagn Cytopathol 1999;21:10-3

22. Bedrossian UK, Fairfax MR, Ayers M. Pap smear follow-up of possible role of mucopurulent exudate as a prognosticator of a negative pregnancy outcome. Diagn Cytopathol 1999;21:4-6 


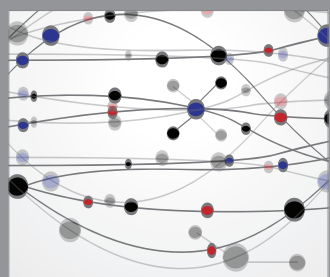

The Scientific World Journal
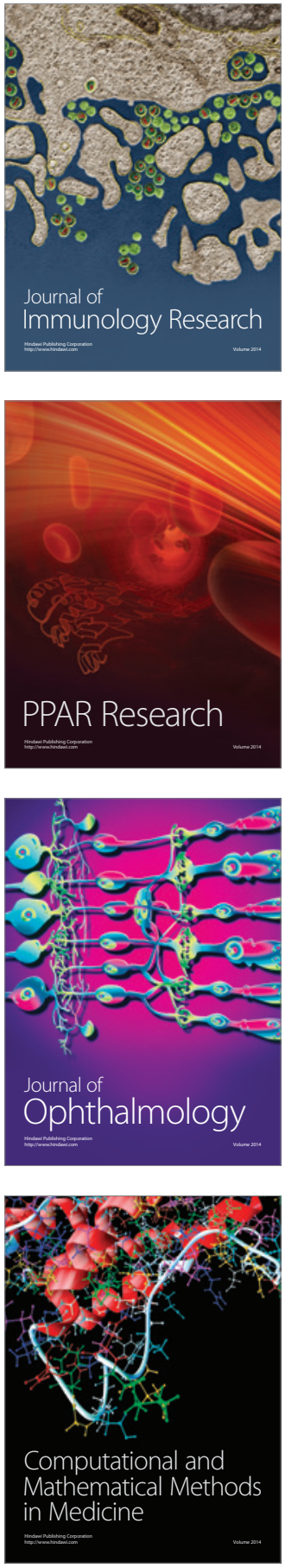

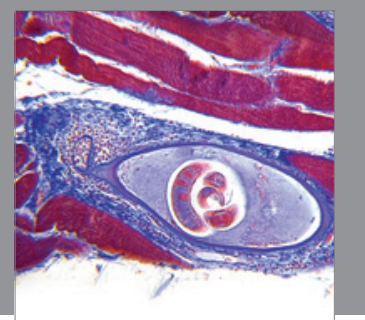

Gastroenterology

Research and Practice
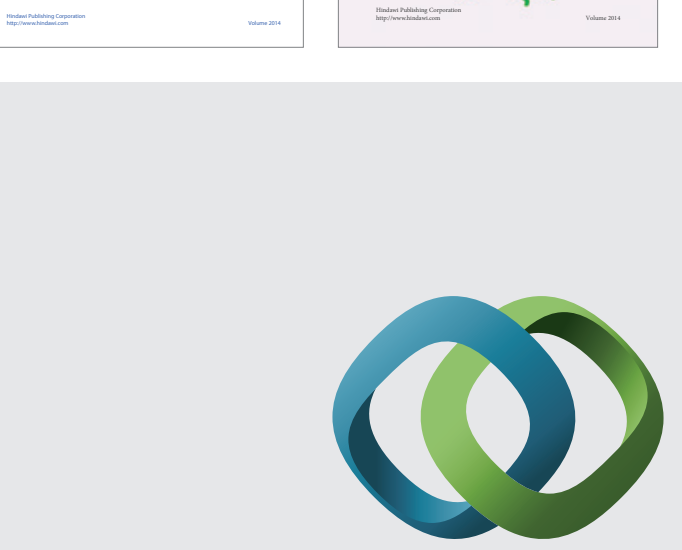

\section{Hindawi}

Submit your manuscripts at

http://www.hindawi.com
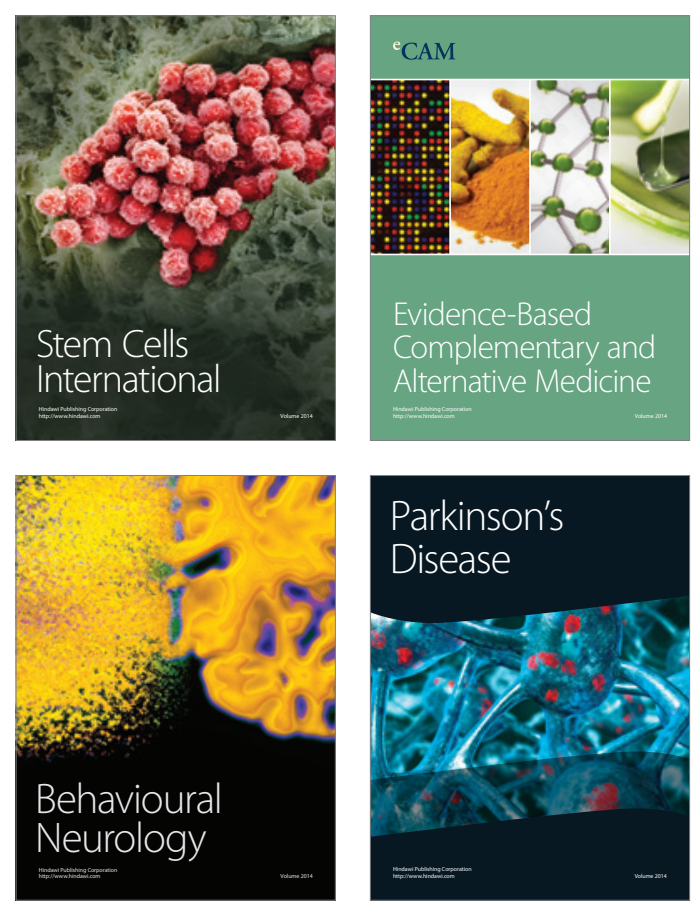

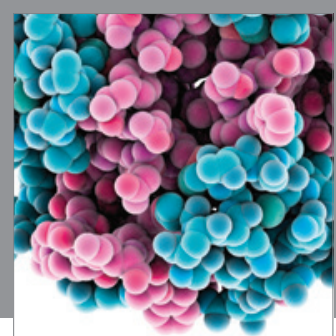

Journal of
Diabetes Research

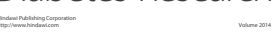

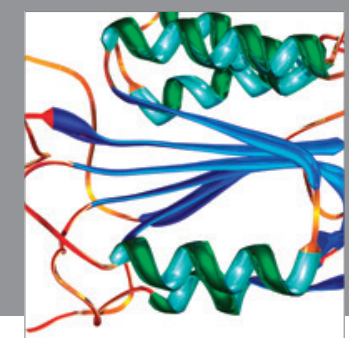

Disease Markers
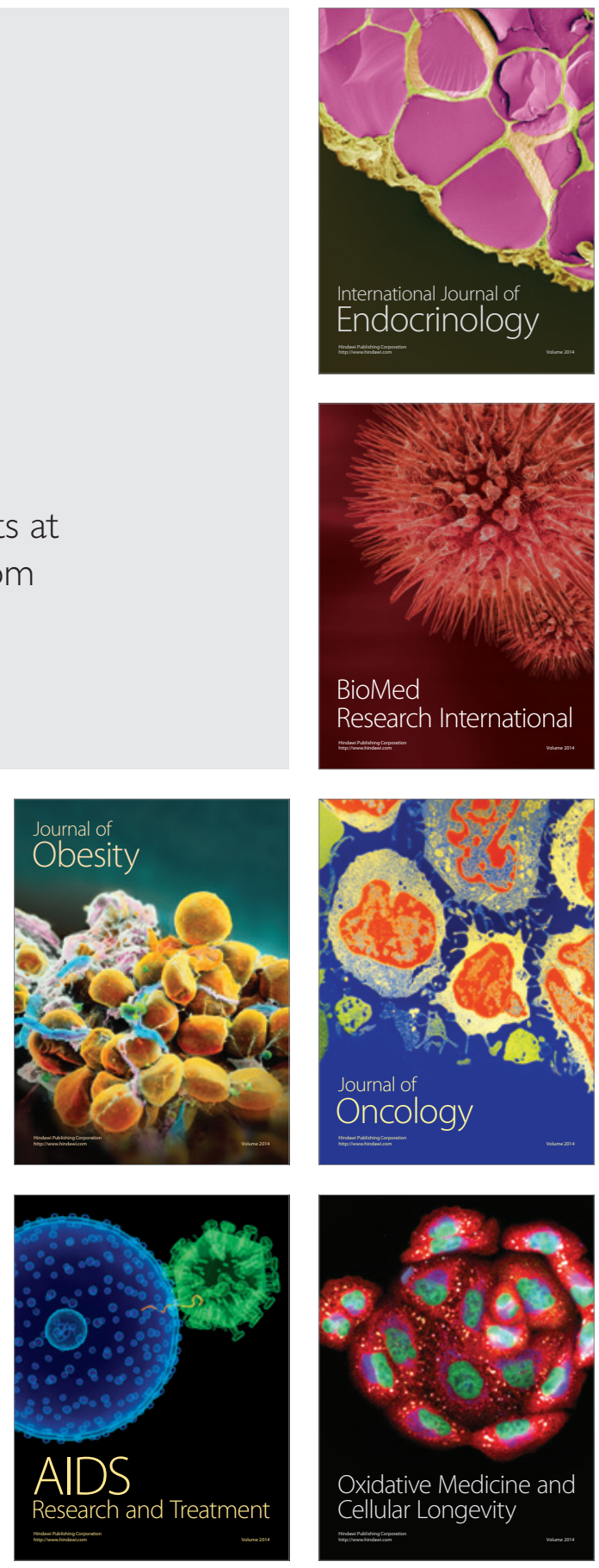